\section{References}

ALBERT, T. \& CHADWICK, S. (1992) How readable are practice leaflets? British Medical Journal, 305. 1266-1268.

HENESSY, B. (1989) Writing Feature Articles. Oxford: Heinemann.

Peterson, T. (1994) How readable are the hospital information leaflets available to elderly patients? Age and Ageing, 23, 14-16.
*Harriet Humfress, Clinical Psychologist in Training. Sub-Department of Clinical Health Psychology. University College London, Gower Street, London WC1E 6BT; and Ulrike Schmidt, Consultant Psychiatrist, Bethlem \& Maudsley NHS Trust, PACT Team, London

*Correspondence

\title{
Traditional healers and mental illness in Uganda
}

\author{
Emilio Ovuga, Jed Boardman and Elizabeth G. A. O. Oluka
}

\begin{abstract}
Aims and method A cross-sectional, interview survey of the beliefs, knowledge, attitudes and practice towards mental illness of 29 traditional healers in the Pallisa district of Uganda was carried out.

Results Many of the healers had experienced emotional problems that had been treated by other healers. Almost all had a family member who was also a traditional healer. They treated a wide range of conditions and all dealt with mental illness. Most believed that mental disorders were caused by supernatural processes. Many recognised the role of environmental agents. Their diagnosis and management of mental illness was eclectic. The healers were either traditional herbalists or spirit diviners or a mixture of both. Almost all referred patients to the district hospitals and were willing to work with government health services.

Clinical implications The results of the survey suggest the presence of fertile ground on which to build cooperation between traditional healers and medical services. Such cooperation may harness primary care resources more effectively. Sequential or simultaneous models of collaboration (or combinations of both) may be considered. Further work on specific treatments, their outcomes and the evaluation of collaborative models is neөded.
\end{abstract}

Mental disorders contribute significantly to the burden of disease across the globe and constitute a formidable challenge for health services (World Bank, 1993; Abas \& Broadhead, 1994; Desjarlais et al, 1995; Bland, 1996; Jenkins, 1997). Decentralisation of health services has been promoted and primary care services have been identified as playing the vanguard role in providing mental health care (World Health Organization, 1978, 1990; Famuyiwa, 1989; Ustun \& Sartorius, 1995). In developing coun- tries resources are limited, as are the skills and knowledge of primary care personnel (Appleby \& Araya, 1991: Abas \& Broadhead, 1994; Desjarlais et al, 1995). In many countries, traditional healers play an important role in the treatment of mental health problems and these healers may be an important resource in the provision of primary mental health services (Young, 1983; World Health Organization, 1990; Winston et al 1995). Uganda is no exception to this (Boardman \& Ovuga, 1997). This paper reports on a survey of such traditional healers in one area of Uganda.

\section{Traditional healers in Africa}

It has long been recognised that traditional healing practices exist side-by-side with modern medical practice (Lambo, 1956; Orley, 1970; Ademuwagun, 1976; Imperato, 1976). A significant proportion of people seek care from traditional and spiritual healers whom they consult for a range of medical problems. A Nigerian study noted that spiritual healers, traditional healers and general practitioners were the first to be contacted by $13 \%, 19 \%$ and $47 \%$ of patients respectively (Gureje et al, 1995). Those dissatisfied with the results of orthodox medicine often take themselves to traditional healers (Patel et al, 1997a) and a significant proportion of these have psychiatric disorders (Patel et al, 1997b). Few studies have surveyed the practice of traditional healers in relation to mental illness. Odejide et al (1977) examined the characteristics and practices of 53 traditional healers in Ibadan. Nigeria and noted that while they engaged in some undesirable practices, they held a broad concept of psychopathology and provided an important force in the treatment of psychiatric disorders. 
More recently, in Zimbabwe, Winston et al (1995) surveyed 110 traditional healers and noted their wish to have greater collaboration with formal medical services. The Zimbabwean researchers, in a separate study, noted that individuals presenting with non-specific pain and other less specific problems did as well if they attended medical or traditional care (Winston \& Patel, 1995).

\section{The study}

\section{Study setting}

The study was carried out in the Pallisa district of Uganda, which lies in the eastern region about 120 miles from Kampala. The region has a population of 350000 whose main language is Lugwere.

\section{Selection of traditional healers}

The indigenous healers were identified for interview with the assistance of the Chairman of Traditional Healers. Fifty-one traditional healers were identified of whom 29 were randomly selected for interview.

\section{The interview}

A semi-structured interview was constructed that asked about the healers' knowledge, attitudes and practice of mental illness. Interviews took place in the homes of the indigenous healers. A local interpreter was used to assist the interviewer (E.G.A.O.O.). The average length of each interview was approximately two hours.

\section{Findings}

\section{Characteristics of traditional healers}

Twenty-nine healers were interviewed, 23 males and six females aged between 20 and 70 years. All were married, five had no formal education, 13 achieved lower primary education, seven upper primary and four had some senior education. The length of practice ranged from one to 46 years. Seventeen had more than 15 years of experience.

\section{Becoming a traditional healer}

Direct contact with other traditional healers before taking up the role was common. Many $(n=19)$ had suffered from some emotional problems that had been treated by a traditional healer before becoming one themselves and almost all $(n=26)$ had had previous contact with a traditional healer because of treatment or training. Almost all $(90 \%)$ had a family member who was also a traditional healer. Four-fifths were initiated into practice and during this almost all experienced trance states of 'spiritual inspiration'.
The majority $(87 \%)$ felt that they were able to solve personal problems without help and many felt that they were successful because of their vast knowledge and long experience in handling the health and social problems of their community.

\section{Beliefs about illness}

About half believed that physical illnesses were caused by evil spirits, witchcraft or curses, but 17 thought they were caused by poor sanitation and seven by poor nutrition. All believed that mental illnesses were caused by evil spirits, witchcraft or curses, five thought they were caused by high fevers. A small number also acknowledged environmental causes of mental disorders, including accidents $(n=2)$, stress $(n=2)$, fatigue $(n=2)$ and alcohol $(n=2)$.

\section{Diagnosing mental illness}

Only three used any form of history-taking and only one used any form of physical examination (taking the pulse). The most common method was to observe for the signs of mental illness (see below). In addition, seven used mayembe, essai or cowrie shells. Mayembe and essai are evil spirits that are sent by enemies to punish or wreak havoc in life by means of mental illness or inflicting corporal injury. They leave the body of the victim by forceful eviction or through negotiations with the more powerful spirits of the healer. Eight used spirit inspection and six used Arabic books (Abu Mashar or Sa Atil Akbari). The approach to diagnosing was generally methodical, usually taking more than an hour to complete.

\section{Features of mental illness}

The healers mentioned a variety of behaviours that they believed denoted mental illness, including: bizarre content of speech, picking and hoarding rubbish, running away or being restless, removing clothes, a suspicious attitude, having an unkempt appearance or being withdrawn, having red, unsteady or glittering eyes, a frightened look and other strange actions or behaviours.

\section{Management and referral}

The patients seen by the traditional healers came from a variety of sources including the local hospital, other healers and by word of mouth.

Almost all the healers recognised that they treated mental illness and said that it was the single most common problem that they treated. None treated mental illness only and all treated a wide variety of complaints. However only one healer would treat any form of complaint and the remainder restricted themselves to a range of specific ailments. 
A variety of management techniques were practised, the most common being therapeutic cuts to the head and body in order to administer herbs $(n=20)$. Also common was the instilling of herbal nasal drops or sniffing herbal medicine $(n=18)$ or the use of an oral herbal medicine $(n=10)$. Bathing or washing with herbal water was used by $35 \%$, as was the burning/inhalation of herbs. Other treatment methods included: instilling eardrops $(n=10)$, giving a talisman $(n=5)$ and making therapeutic cuts in the ground where the patient's shadow had fallen $(n=2)$.

The approaches to diagnosis and treatment were often combined and several general approaches were observed; the spirit mediums (spirit diviners) believed that they had the ability to communicate with ancestors or alien spirits while in a state of spirit possession. Herbalists were concerned with the direct treatment of physical symptoms. General diviners concentrated on diagnosing using cowrie shells. Others were also traditional birth attendants. The majority used a combination of approaches, only two were pure herbalists and the remainder were herbalists and diviners or traditional birth attendants and herbalists.

Almost all the healers referred patients on to the district hospitals and many would refer them to other local traditional healers. Only one did not want any form of collaboration with government health workers and the same healer was the only one who did not like to collaborate with other traditional healers.

Most had some advice to give to the government regarding services for the mentally ill, which included developing joint work between health services and themselves $(n=12)$, taking rooms in health centres and hospitals $(n=2)$, treating the mentally ill with understanding and secluding them in a cool, quiet place with a relative while receiving treatment $(n=3)$. Ten offered to subject their herbal remedies for analysis and one requested that his treatments were evaluated.

\section{Comment}

This study adopted a survey approach to the study of traditional healers. It provides a useful cross-sectional view of the attitudes and practices of traditional healers and their willingness to engage with formal services. The results can be compared to similar studies carried out in Nigeria and Zimbabwe.

\section{Comparative findings}

As with the Zimbabwean and Nigerian studies the healers were mainly older men who had considerable experience of practice. Odejide et al (1977) found that $85 \%$ of their sample had more than 20 years experience and that almost all had inherited the practice from their parents. We noted that prior experience of traditional healing either by experience of treatment or family practice was an important precursor to entering the practice. The Ugandan healers' conceptions of physical illness were broad but their views of mental disorders were narrower, being mainly concerned with supernatural processes. However, like the Nigerian healers they did entertain the possibility that environmental agents such as stress and physical factors might be involved.

The broad categories of healers in Uganda were similar to those found in other parts of Africa. The Yoruba healers consist of herbalists (Onisegun) and diviner priests (Babalawo) (Odejide et al, 1977). The Zimbabwean healers were composed of prophets and n'anga (spirit mediums and herbalists) (Winston et al, 1995). It was recognised in all these studies that these categories are not mutually exclusive and that the techniques, particularly of herbalists and diviners overlap. This eclecticism is also reflected in the diagnostic and treatment techniques used. Winston et al (1995) noted that the most common diagnostic methods used were trance states or dreams, but also the use of objects such as shells, calabashes or mirrors were common. Obejide et al (1977) reported the use of a variety of treatments including physical restraints, scarifications, sacrifice, incantations and divinations. In Zimbabwe, as in Uganda, the healers treated a wide range of disorders and few limited themselves to specific complaints.

\section{Traditional healers and formal medical services}

Many of the individuals seen by traditional healers in Uganda, Zimbabwe and Nigeria also had contact with formal services and the healers often referred people on to government medical centres. In all three countries the healers were willing to consider links with formal services. What are the issues relating to the use of traditional healers in primary mental health care?

A central concern is the manpower implication of the large need relative to low resources and the integration of traditional healers into mainline services is seen as an inexpensive means of expanding the availability of efficacious services (Young, 1983). This may be easier with those healers with specific manual skills such as the traditional birth attenders and bonesetters but may be more difficult with the herbalists and diviners whose practices and secrets may be less acceptable to medical practitioners. Areas of consideration are those of the curing and healing powers of the traditional healers (Young, 1983). It is the healing component of their work, with its associations to meanings of sickness, which may 
be considered to be important, particularly in relation to those with mental disorders and to acceptability and satisfaction. The Ugandan healers, like their counterparts in Nigeria (Odejide et al, 1977), were confident in their ability to deal with mental disorders and this confidence in their powers may be harnessed to produce effective outcomes. Along with this, however, the traditional healers need to be helped to recognise their limitations in treating the diverse range of medical conditions and to be encouraged to refer severe cases to health workers at an early stage.

Two system models of liaison between primary health care services and traditional healers can be considered: a simultaneous model whereby the traditional healers work side-by-side, perhaps in the same premises, and a sequential model in which the medical workers and traditional healers refer each other patients. There is some evidence that the latter model is already operating in Uganda as almost all of the healers refer their patients to medical clinics. The simultaneous model appears to be feasible, as the healers are open to working in medical settings and it is known that traditional healers and health workers are already collaborating in the care of people with AIDS. Both models could co-exist but if integration of services were to occur then some training of the traditional healers is important. Odejide et al (1977) recognised that some poor practices had to be eradicated and highlighted the use of physical restraints by healers. We found no evidence of such practices but noted the use of scarification that, in a country such as Uganda with one of the world's highest rates of HIV infection, should be regarded as undesirable. In addition to encouraging good practice in the traditional healers, the primary care workers will require teaching in the ways of the healers and may be trained to adopt some of their desirable techniques.

\section{Further work}

Further work is required on the skills and effectiveness of traditional healers, particularly with regard to the specific treatments that are used and the associated outcomes. The effects of collaboration need to be evaluated especially in such areas as the pathways to care, the use of the simultaneous and sequential models and the cost-effectiveness of the collaboration. In particular, an increasingly productive use of resources by primary health care services should result from the liaison with traditional healers.

\section{References}

ABAS, M. \& BROADHEAD, J. (1994) Mental disorders in the developing world. British Medical Journal, 308, 1052.
ADEMUWAGUN, Z. A. (1976) The challenge of the coexistence of orthodox and traditional medicine in Nigeria. East African Medical Journal, 58, 21-32.

APPLEBY, L. \& ARAYA, R. (1991) Mental Health Services in the Global Village. London: Gaskell.

BLAND, R. C. (1996) International health and psychiatry. Canadian Journal of Psychiatry, 41, 11-15.

BOARDMAN, A. P. \& OvUGA, E. (1997) Rebuilding psychiatry in Uganda. Psychiatric Bulletin, 21, 649-655.

DESJARLAIS, R., EISENBERG, L., GOOD, B., et al (1995) World Mental Health: Problems and Priorities in Low-Income Countries. Oxford: Oxford University Press.

FAMUYIWA, O. O. (1989) Mental health in primary care. Focus on the Third World. Psychiatric Bulletin, 13, 20-24.

GuREJe, O., ODENIDE, A. O.. OlatAWURA, M. O., et al (1995) Results from the Ibadan Centre. In Mental Illness in General Health Care: An International Study (eds T. B. Ustun \& N. Sartorius), pp. 157-174. London: John Wiley and Sons.

IMPERATO, J. P. (1976) Traditional medical beliefs and practices in the city of Timbuctoo. Bulletin of the New York Academy of Medicine, 52, 241-252.

JENKINS, R. (1997) Nations for mental health. Social Psychiatry and Psychiatric Epidemiology, 32, 309-311.

LAMBO. T. A. (1956) Neuropsychiatric observations in the western region of Nigeria. British Medical Journal, 2. 1388-1394.

Odevide, A. O., OlatawURA, M. O., SANDA A. O., et al (1977) Traditional healers and mental illness in the city of Ibadan. African Journal of Psychiatry, 3, 99-106.

ORLEY, J. H. (1970) Culture and Mental Illness: Study from Uganda. East African studies no. 36. Nairobi: East African Publishing House.

Patel, V., Simunyu, E. \& Gwanzura, F. (1997a) The pathways to primary mental health care in highdensity suburbs in Harare, Zimbabwe. Socia Psychiatry and Psychiatric Epidemiology, 32, 97-103.

- TODD, C., Winston, M., et al (1997b) Common mental disorders in Harare, Zimbabwe: associations and risk factors. British Journal of Psychiatry, 171, 60-64.

USTUN, T. B. \& SARTORIUS, N. (1995) Mental Illness in General Health Care: An International Study. London: John Wiley and Sons.

Winston, C. M. \& PATEL. V. (1995) Use of traditional and orthodox health services in urban Zimbabwe. International Journal of Epidemiology. 24, 1006-1012.

- - - . MusonzA. T., et al (1995) A community survey of traditional medical practitioners in high-density suburbs of Harare. Central African Joumal of Medicine, 41, 278-283.

WORLD BANK (1993) Investing in Health. Oxford: Oxford University Press.

WORLD HEalth ORganization (1978) Primary Health Care: A Report of the International Conference on Primary Health Care, Alma Ata, USSR. 6-12 September 1978. Geneva: WHO.

- (1990) The Introduction of a Mental Health Component into Primary Health Care. Geneva: WHO.

YounG, A. (1983) The relevance of traditional medicine cultures to modern primary health care. Social Science and Medicine, 17, 1205-1211.

Emilo Ovuga, Head of Department of Psychiatry. Makerere University, Kampala, Uganda; *Jed Boardman, Senior Lecturer in Social Psychiatry. Academic Department of Psychiatry, The Guy's King's College and St Thomas' Hospitals' Medicine and Dental School, Guy's Campus, 5th Floor, Thomas Guy House, Guy's Hospital, London SE1 9RT; and Elizabeth G. A. O. Oluka, Tutor, School of Public Health Nursing, Mulago Hospital, Kampala, Uganda

*Correspondence 